\title{
Effects of reduced diameter of bag cultures on content of essential fatty acids and cell density in a continuous algal production system
}

\author{
Anita Jacobsen • Otto Grahl-Nielsen • \\ Thorolf Magnesen
}

Received: 1 October 2010 /Revised and accepted: 11 January 2011 /Published online: 16 February 2011

(C) The Author(s) 2011. This article is published with open access at Springerlink.com

\begin{abstract}
Cell density and fatty acid (FA) content of Pavlova lutheri and Chaetoceros muelleri were analysed in a continuous algal production system (250-L bags) with reduced diameter. The cell density and FA content and composition in the algal production system were determined in replicate bags over a period of 5 weeks. The results showed that the cell density and essential FAs increased during the experiment for both species. After 5 weeks the mean cell numbers had increased to $6.0 \pm 0.3 \times 10^{6}$ cells $\mathrm{mL}^{-1}$ in the $P$. lutheri bags and $6.0 \pm 0.4 \times 10^{6}$ cells $\mathrm{mL}^{-1}$ in the $C$. muelleri bags. The content of total FAs increased significantly $(p<0.05)$ in all of the bags during the experiment. At the end of the experiment the mean total FA content were $2.7 \pm 0.3 \mathrm{pg}^{-1}$ cell $^{-1}$ in the $P$. lutheri bags and $1.8 \pm 0.1 \mathrm{pg} \mathrm{cell}^{-1}$ in the C. muelleri bags. Maximum total FA content registered was $3.0 \mathrm{pg} \mathrm{cell}^{-1}$ in one of the P. lutheri bags. The content of the essential FAs (ARA, EPA, DHA) increased over time in both of the species. At the end of the experiment the content of EPA $\left(0.6 \pm 0.1\right.$ pg cell $\left.^{-1}\right)$ and DHA $\left(0.3 \pm 0.0 \mathrm{pg} \mathrm{cell}^{-1}\right)$ were highest in the $P$. lutheri bags, while ARA $\left(0.1 \pm 0.0 \mathrm{pg} \mathrm{cell}^{-1}\right)$ was highest in C. muelleri. EPA and DHA constituted $22 \%$ and $11 \%$, respectively, of total FA content in P. lutheri, while ARA constituted $6 \%$ of total FA
\end{abstract}

Electronic supplementary material The online version of this article (doi:10.1007/s10811-011-9655-6) contains supplementary material, which is available to authorized users.

\footnotetext{
A. Jacobsen $(\triangle) \cdot T$. Magnesen

Department of Biology, University of Bergen,

PO Box 7803, 5020 Bergen, Norway

e-mail: anita.jacobsen@bio.uib.no

O. Grahl-Nielsen

Department of Chemistry, University of Bergen,

Allégaten 41,

5007 Bergen, Norway
}

content in C. muelleri. The results from this experiment indicate that flagellates such as $P$. lutheri perform better in narrow bags with improved light conditions, while diatoms like C. muelleri perform better in wider bags under light limitation. Implications for bivalve hatcheries are discussed.

Keywords Continuous algal production - Bivalve hatchery . Fatty acids Pavlova lutheri .

Chaetoceros muelleri

\section{Introduction}

Larvae and juveniles produced in bivalve hatcheries are dependent on live feed such as algae (Dhert and Sorgeloos 1994). Live feed is often produced on site in separate installations and this can be both laborious and costly, in addition to not being optimised with respect to the species produced.

Large scale continuous bag cultures are well-used production systems (www.seacaps.com) in many commercial bivalve hatcheries (e.g. Magnesen et al. 2006, Jacobsen et al. 2010). The quality of the live feed is an important factor for rearing success of the larvae and juveniles produced. A major advantage of this system is the possibility to grow several species in separate bags coupled together and its relatively easy maintenance.

The cylindrical plastic bags, which can be up to $500 \mathrm{~L}$, are either illuminated with natural or artificial light under controlled temperature conditions. However, a disadvantage of this system is low cell densities because of light limitation due to a large diameter of the bags $(D \leq 50 \mathrm{~cm})$. Photosynthetic active light only penetrate about $3 \mathrm{~cm}$ into a dense culture (Richmond 2004). This results in high efficiency photosynthesis per se in the photic volume only 
whereas the rest of the bag effectively will not participate in the production. Other algal production systems with lesser diameter have been developed where algae are circulated in tubes in a fence (e.g. BioFence, http://home.bt-webworld. com/cellpharm/products.htm), in a flat plate (e.g. Hu and Richmond 1996) or in a spiral/helical shaped pipe system (e.g. Acién Fernández et al. 2003, Briassoulis et al. 2010) using natural or artificial light. These systems are, however, less suited for growing algae in cold water areas due to indoor production and because they are difficult to scale up in volume to meet the hatcheries requirements for live feed (e.g. Janssen et al. 2003).

The fatty acid (FA) composition is highly dynamic and responds significantly to variation in light intensity (e.g. Thompson et al. 1990; Brown et al. 1993). Other studies have also demonstrated that changes in culture media (Ben-Amotz et al. 1985), temperature (James et al. 1989, Thompson et al. 1992, Zhu et al. 1997), pH (Guckert and Cooksey 1990), stage of harvest and different culture techniques (e.g. Emdadi and Berland 1989; Hodgson et al. 1991; Dunstan et al. 1993; Brown et al. 1997; Pernet et al. 2003) have an impact on FA content and composition.

In a large scale continuous bag production system $(500 \mathrm{~L}, D=50 \mathrm{~cm})$ used by many hatcheries, the algal cell density in the bags are low when artificial light is used (e.g. $1.8-2.2 \times 10^{6}$ cells $\mathrm{mL}^{-1}$, Jacobsen et al. 2010) due to light limitation. In this experiment we wanted to investigate the dependence of cell density and content of essential FAs on the volume of this culture system. Effects of size of culture systems on cell density and FAs have been investigated in other types of systems (e.g. Acién Fernández et al. 1998, Acién Fernández et al. 2000, Zou et al. 2000), but to our knowledge, never in this type of bag system before.

The purpose of the present investigation was therefore to see if better light conditions by reduction of the diameter of the culture bags from $50 \mathrm{~cm}$ to $25 \mathrm{~cm}$ increased cell density and FA content of the two species Pavlova lutheri and Chaetoceros muelleri used as live feed in bivalve hatcheries. The cell density and FAs in the algal production system were analysed between replicate bags over a period of 5 weeks. Implications for bivalve hatcheries are discussed.

\section{Materials and methods}

The microalgal cultures were grown and operated at the Norwegian scallop hatchery Scalpro AS, located at Rong, outside Bergen, Norway.

Stock cultures of $P$. lutheri (CCAP 931/1) and $C$. muelleri (CCAP 1010/3) were obtained from the Culture Collection of Algae and Protozoa (CCAP, UK). The stock cultures $(30 \mathrm{~mL})$ were grown and maintained under continuous white fluorescent light (Osram L 58W/965
Biolux) at $100 \mu \mathrm{mol}$ photons $\mathrm{m}^{-2} \mathrm{~s}^{-1}$, at $15 \pm 1^{\circ} \mathrm{C}$ and in Conway medium (Laing 1991). Starter cultures (2 L) were inoculated with axenic stock cultures $\left(10 \times 10^{6}\right.$ cells $\left.\mathrm{mL}^{-1}\right)$. The starter cultures were then grown in Conway medium at $20 \pm 1{ }^{\circ} \mathrm{C}$, in continuous white fluorescent light at $110 \mu \mathrm{mol}$ photons $\mathrm{m}^{-2} \mathrm{~s}^{-1}$ and with bubbling of $\mathrm{CO}_{2}-$ enriched air $(0.5 \%$ of the volume of air). The starter cultures $\left(20-30 \times 10^{6}\right.$ cells $\left.\mathrm{mL}^{-1}\right)$ were then used to inoculate the 250-L continuous bag cultures ( $D=25 \mathrm{~cm}$ and $H=240 \mathrm{~cm})$. About $10 \%$ of the bag volume was continuously harvested per day at late logarithmic growth phase. The bag cultures were grown under the same conditions as the starter cultures, enriched with $\mathrm{CO}_{2}$, but with higher light intensities (220 $\mu \mathrm{mol}$ photons $\mathrm{m}^{-2} \mathrm{~s}^{-1}$, Osram L 58W/965 Biolux). The bags were illuminated by light panel evenly distributed along the sides of the bags. Three replicate bags were set up for each species. $\mathrm{pH}$ was monitored and kept as stable as possible and varied between 8.4 and 8.7.

\section{Sampling}

Samples for determination of microalgal cell numbers and FA content and composition were collected three times (T1, $\mathrm{T} 2$ and T3) from three bags for each species over a period of 5 weeks on 8 June, 22 June and 6 July (2009) at the scallop hatchery Scalpro AS. The bags were started at the same time and were therefore of the same age. The sampling of the bags started when the cultures were 1 week old ( 8 June). The bags were operated as continuous cultures and were harvested at late logarithmic phase. $\mathrm{pH}$ was monitored daily with a digital $\mathrm{pH}$ meter.

Cell numbers were determined by counting live cells in a Bürker counting chamber. A minimum of 400 cells were counted each time giving a counting error of $\pm 10 \%$ (Andersen and Throndsen 2003).

Samples for FA analyses (250 $\mathrm{mL}$ from each bag) were immediately brought to the laboratory at the University of Bergen after sampling for further processing.

FA analysis

The algal FAs were converted to FA methyl esters (FAMEs) by direct methanolysis, as described in Meier et al (2006). After gentle stirring to ensure homogeneous suspension in the flasks, five replicate subsamples were poured into $15 \mathrm{~mL}$ thick-walled glass tubes with teflon-lined screw caps containing $8.3 \mu \mathrm{g}$ of the internal standard FA 19:0. The internal standard had been added in advance to the tubes in a chloroform solution of accurately known concentration, whereupon the solvent had been evaporated. Samples were concentrated by centrifugation at $4,500 \mathrm{rpm}$ for $15 \mathrm{~min}$. The supernatant was gently sucked off and the remaining water was evaporated under a stream of $\mathrm{N}_{2}$ gas. 
For C. muelleri the algal material was not completely precipitated by the centrifugation, so replicates of $50 \mathrm{~mL}$ each in $\mathrm{T} 1$ and $25 \mathrm{~mL}$ in $\mathrm{T} 2$ and $\mathrm{T} 3$ of the algal suspension were filtered by suction through a paper filter, $2 \mathrm{~cm}$ diameter, which had been thoroughly rinsed with chloroform and methanol. The filter paper with the algal material was transferred to $15 \mathrm{~mL}$ thick-walled glass tubes for further treatment as the other samples.

One half millilitre anhydrous methanol, containing hydrogen chloride at a concentration of $2 \mathrm{~mol} \mathrm{~L}^{-1}$ was added; the tubes were sealed with Teflon-lined screw caps and subjected to methanolysis for $2 \mathrm{~h}$ at $90^{\circ} \mathrm{C}$. After cooling, approximately half of the methanol was evaporated with gas and replaced by $0.5-\mathrm{mL}$ distilled water. The water/ methanol phase containing the FAME was extracted twice with 1-mL hexane by thorough shaking followed by centrifugation and withdrawal of the hexane phase by a Pasteur pipette. The concentration of the FAME in the combined extracts was adjusted by addition of hexane to obtain an approximately similar response of 50-100 area units for 16:0 for all samples.

One microlitre of the hexane extracts was injected splitless and chromatographed on a $25 \mathrm{~m} \times 0.25 \mathrm{~mm}$ fused-silica column with polyethyleneglycol (CP-WAX 52 CB Chrompack) with $0.2 \mu \mathrm{m}$ thickness as stationary phase and helium at $20 \mathrm{psi}$ as mobile phase, giving a flow rate of $1 \mathrm{~mL} / \mathrm{min}$ at the start of the run. The column was mounted in a Hewlett-Packard 5892 Series II gas chromatograph equipped with a Hewlett-Packard 7673 autosampler and a flame-ionisation detector. Injector and detector temperatures were $260^{\circ} \mathrm{C}$ and $330^{\circ} \mathrm{C}$, respectively. The oven temperature was $90^{\circ} \mathrm{C}$ at injection and this temperature was maintained for $4 \mathrm{~min}$ before being raised to $165^{\circ} \mathrm{C}$ at $30^{\circ} \mathrm{C} \mathrm{min}{ }^{-1}$, thereafter being raised to $225^{\circ} \mathrm{C}$ at $3{ }^{\circ} \mathrm{C} \min ^{-1}$ and maintained there for $10.5 \mathrm{~min}$. A standard solution (GLC-68D from $\mathrm{Nu}$-Check-Prep, USA) containing 20 FAMEs was chromatographed after every eight sample. The detector signal was digitalised and sent to the lab-data system Chromeleon. Peaks were identified by means of the standard mixture, previous experience of relative retention times of FAME and mass spectrometry. The peak areas of 31 selected FAMEs between 14:0 and 22:6n3 were integrated and corrected by response factors. These empirical response factors, relative to $18: 0$, were calculated for the 20 FAMEs, present in known amounts in the standard mixture. The response factors for each of the five FAMEs, for which we had no standards, were estimated by comparison with the standard FAME with the closest retention time that resembled each of those most closely in terms of chain length and number of double bonds. These corrected areas were then used to calculate FA content and for multivariate analysis.
Statistical methods

The relative content of each of the 31 FAs in the samples was calculated as percentage of the total. To detect possible differences in the FA composition among the different species and bags the data were subjected to multivariate principal component analysis using the software package Sirius 7.0 (Kvalheim and Karstang 1987). The relative values of the 14 most abundant FAs were log-transformed in order to level out the quantitative differences among the FAs. The samples were positioned in a 14-dimensional space, one dimension of each FA, and principal components (PCs) were then placed as vectors through the centroid of the samples in such a way that the first PC fell in the direction of the largest spread of the samples, and the second PC, orthogonal to the first, in the direction of the second largest spread of the samples. The samples were projected onto the plane made of these two coordinates. The systematic variation among the samples embedded in the original 14 variables, FAs, was thus displayed in two dimensions.

An one-way ANOVA (Statistica 8) was performed to detect significant difference $(p<0.05)$ between replicate bags.

\section{Results}

The microalgal production were operated as continuous cultures $(250-\mathrm{L}$ bags and $D=25 \mathrm{~cm})$ and harvested at late logarithmic growth phase. Gradual increases in cell numbers were observed from T1, T2 and to T3 (Table 1). At the first sampling point (T1) the mean cell numbers were $4.1 \pm 1.2$ and $2.0 \pm 0.8 \times 10^{6}$ cells $\mathrm{mL}^{-1}$ in the P. lutheri and C. muelleri bags, respectively. After 6 weeks (T3) the mean cell numbers had increased to $6.0 \pm 0.3 \times 10^{6}$ cells $\mathrm{mL}^{-1}$ in the $P$. lutheri bags and $6.0 \pm 0.4 \times 10^{6}$ cells $\mathrm{mL}^{-1}$ in the $C$. muelleri bags (Table 1).

At T1 the mean total FA content were $1.4 \pm 0.8 \mathrm{pg} \mathrm{cell}^{-1}$ in the $P$. lutheri bags and $0.4 \pm 0.3 \mathrm{pg} \mathrm{cell}{ }^{-1}$ in the $C$. muelleri bags (Table 1). The content of total FAs increased significantly $(p<0.05)$ in all of the bags during the experiment. At the end of the experiment (T3) the mean total FA content were $2.7 \pm 0.3 \mathrm{pg} \mathrm{cell}^{-1}$ in the $P$. lutheri bags and $1.8 \pm 0.1 \mathrm{pg} \mathrm{cell}^{-1}$ in the C. muelleri bags (Table 1). Maximum total FA content registered was $2.98 \mathrm{pg} \mathrm{cell}^{-1}$ in one of the $P$. lutheri bags (T3, Table 1).

The content of the essential FAs (arachidonic acid (ARA), eicosapentaenoic acid (EPA), and docosahexaenoic acid (DHA)) increased over time in both of the species (Tables 1 and 2). The content of EPA and DHA (pg cell ${ }^{-1}$ ) were highest in the $P$. lutheri bags, while ARA (pg cell ${ }^{-1}$ ) was highest in C. muelleri (Tables 1 and 2). At the end of 


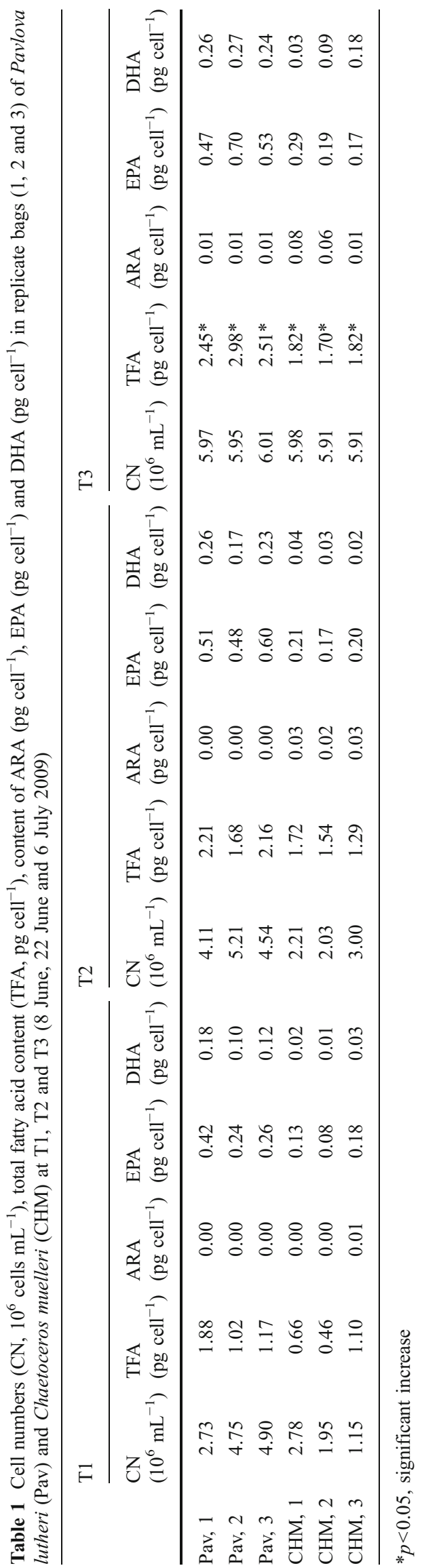

the experiment (T3), EPA and DHA constituted $22 \%$ and $11 \%$ of the total FA content in P. lutheri, while ARA constituted $6 \%$ of the total FA content in C. muelleri.

The sum of saturated FA (SFA), monounsaturated FA (MUFA) and polyunsaturated FA (PUFA) changed between species over time (Fig. 1). The content of SFAs was in general higher in the C. muelleri bags than in the P. lutheri bags (Fig. 1; Tables 3, 4 and 5 in the Electronic supplementary material). SFA (\%) increased over time in the C. muelleri bags from a mean initial content of $35.9 \pm$ $0.3 \%$ to a mean content of $44.4 \pm 0.8 \%$ on the last sampling date. An increase in the level of SFA was also observed in the P. lutheri bags (Fig. 1; Tables 3, 4 and 5 in the Electronic supplementary material), corresponding to a mean increase from $30.4 \pm 0.1 \%$ to $35.1 \pm 1.1 \%$. The dominating SFAs in both species were 14:0 and 16:0. Particularly 14:0 increased over time in the C. muelleri bags (Tables 3,4 and 5 in the Electronic supplementary material).

The content of MUFAs was slightly higher in the $C$. muelleri bags than in the P. lutheri bags (Fig. 1) at T1 and T2. A significant $(p<0.05)$ decrease in MUFAs was, however, registered on $\mathrm{T} 3$ in the $C$. muelleri bags (Fig. 1). It was particularly $16: \ln 7$ that dominated in both species, while $17: \ln 9$ decreased significantly over time in the C. muelleri bags (Tables 3, 4 and 5 in the Electronic supplementary material).

The content of PUFAs ( $\%$ of total FA) was higher in the P. lutheri bags compared with the C. muelleri bags (Fig. 1; Tables 3, 4 and 5 in the Electronic supplementary material). A significant $(p<0.05)$ decrease in proportion was, however, detected in the $P$. lutheri bags over time, while an increase was observed in the $C$. muelleri bags. The dominating PUFAs in both species were 18:4n3, EPA and DHA, while ARA was in addition amongst the dominating PUFAs in $C$. muelleri. In C. muelleri it was particularly ARA (1\% to $3 \%$ ) and DHA (3\% to 6\%) that increased over time, while the C18 PUFAs decreased from $13 \%$ to $8 \%$ in the P. lutheri bags.

The PC analysis (Figs. 2 and 3) detected variation between the replicate bags of the different species over time. The $P$. lutheri bags showed relatively much smaller variation between the bags and over time than $C$. muelleri (Figs. 2 and 3). To obtain a display of the much smaller variation for P. lutheri, a new PC analysis was performed on the P. lutheri samples exclusively (Fig. 3). The two first principal components (PC1 and $\mathrm{PC} 2$ ) described $79 \%$ of the total variation between the samples in this case. The variation between the bags was smaller than for $C$. muelleri, and the development over time was much more similar for the three replicate bags. On the first sampling date (T1) only two FAs $(22: 0,22: 6 \mathrm{n} 3)$ differed significantly $(p<0.05$; Table 3 in the Electronic supplementary material) between the replicates, whilst three FAs differed significantly $(p<$ 0.05 ) at $\mathrm{T} 2$ and $\mathrm{T} 3$ (Tables 4 and 5 in the Electronic 
Table 2 Mean values \pm STD of fatty acid content $\left(n=3\right.$, pg cell $\left.{ }^{-1}\right)$ of ARA, EPA, n-6 DPA and DHA at start and end in Pavlova lutheri and Chaetoceros muelleri bags from this experiment (250-L bags) compared with results from a similar experiment in 500-L bags (Jacobsen et al. 2010)

\begin{tabular}{|c|c|c|c|c|c|c|c|c|}
\hline & \multicolumn{4}{|l|}{ P. lutheri } & \multicolumn{4}{|l|}{ C. muelleri } \\
\hline & \multicolumn{2}{|l|}{$250 \mathrm{~L}$} & \multicolumn{2}{|l|}{$500 \mathrm{~L}$} & \multicolumn{2}{|l|}{$250 \mathrm{~L}$} & \multicolumn{2}{|l|}{$500 \mathrm{~L}$} \\
\hline & Start & End & Start & End & Start & End & Start & End \\
\hline ARA & $0.00 \pm 0.00$ & $0.01 \pm 0.00$ & $0.00 \pm 0.00$ & $0.01 \pm 0.00$ & $0.00 \pm 0.00$ & $0.05 \pm 0.03$ & $0.03 \pm 0.03$ & $0.09 \pm 0.02$ \\
\hline EPA & $0.31 \pm 0.09$ & $0.62 \pm 0.12$ & $0.18 \pm 0.02$ & $0.34 \pm 0.08$ & $0.13 \pm 0.05$ & $0.18 \pm 0.10$ & $0.22 \pm 0.05$ & $0.40 \pm 0.09$ \\
\hline n-6 DPA & $0.00 \pm 0.00$ & $0.00 \pm 0.00$ & $0.01 \pm 0.00$ & $0.02 \pm 0.01$ & $0.00 \pm 0.00$ & $0.00 \pm 0.00$ & $0.00 \pm 0.00$ & $0.00 \pm 0.00$ \\
\hline DHA & $0.13 \pm 0.04$ & $0.26 \pm 0.02$ & $0.08 \pm 0.01$ & $0.12 \pm 0.03$ & $0.02 \pm 0.01$ & $0.10 \pm 0.07$ & $0.01 \pm 0.01$ & $0.03 \pm 0.00$ \\
\hline
\end{tabular}

supplementary material). This shows that nearly all of the FAs were stable between the replicates over time in the P. lutheri bags.

The C. muelleri bags showed large variation between the replicates and over time (Fig 2). From T1 to T2 the bags did not develop in the same direction. The development from T2 to T3 was the largest. The bags developed more or less in the same direction, but they were not similar. The two first principal components (PC1 and PC2) described $75 \%$ of the total variation between the samples. At T1 16 FAs differed significantly between the replicates (Table 3 in the Electronic supplementary material), while 12 and 14 FAs differed significantly between the replicates at $\mathrm{T} 2$ and $\mathrm{T} 3$, respectively (Tables 4 and 5 in the Electronic supplementary material). Different FAs caused the development over time for the two species, e.g. 18:3n 3 increased over time for $C$. muelleri while this FA decreased from T1 to T3 for P. lutheri. For i-17:0 the opposite was the case: decrease over time for $C$. muelleri and increase for P. lutheri (Fig. 3). The essential PUFAs (ARA, EPA and DHA) were stable between the replicates over time in the $P$. lutheri bags. In the $C$. muelleri bags (Tables 3, 4 and 5 in the Electronic supplementary material) the variations were larger between the replicates and over time, and only DHA was stable over time (T1 and T2).
Fig. 1 Mean proportions (\% of total fatty acid) of saturated $(S F A)$, monounsaturated (MUFA) and polyunsaturated fatty acids (PUFA) of Pavlova lutheri and Chaetoceros muelleri at T1 (8 June), T2 (22 June) and T3 (6 July). Error bars indicate STD, $a$ indicate significant increase $(p<0.05)$ and $b$ indicate significant decrease $(p<0.05)$
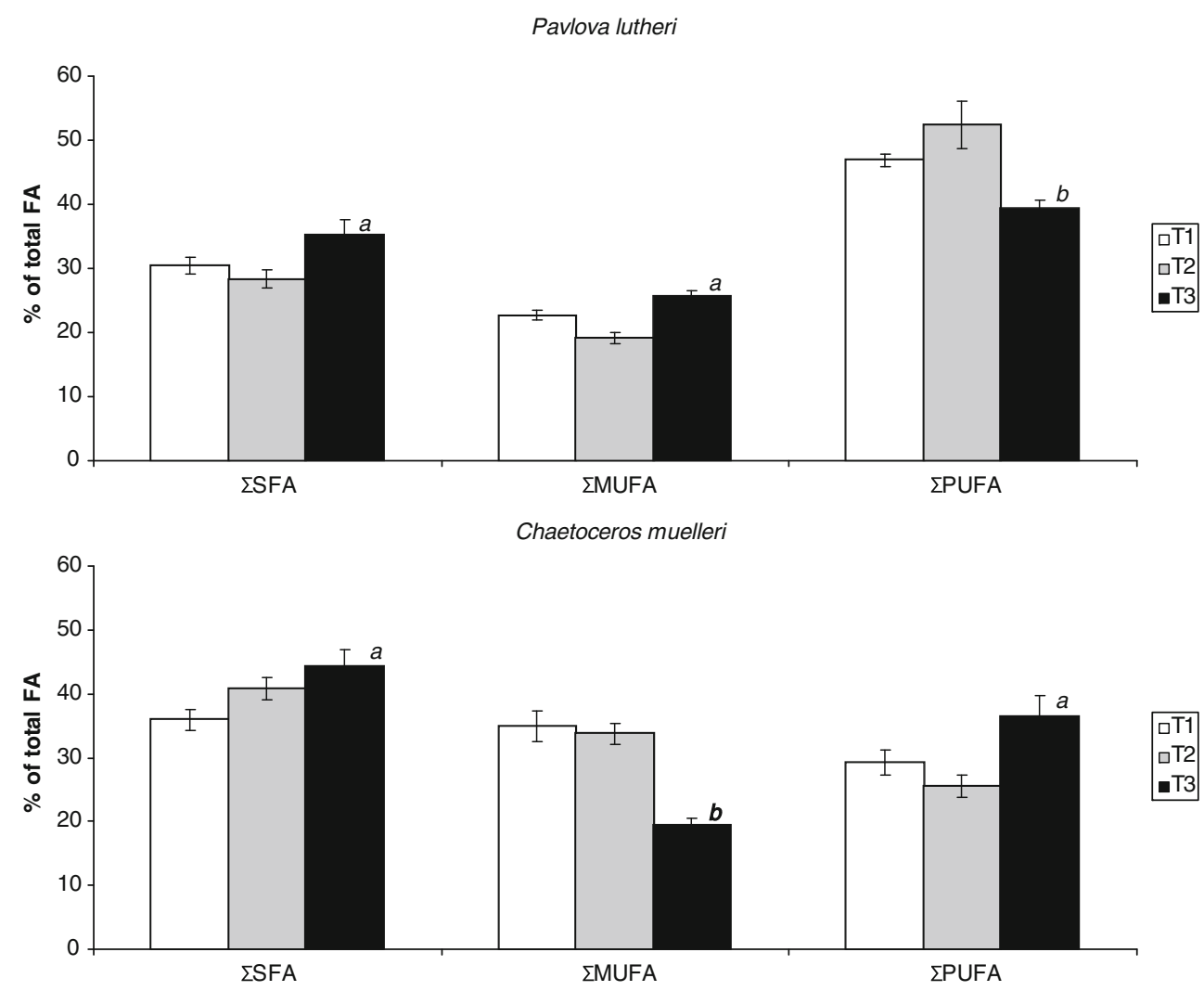


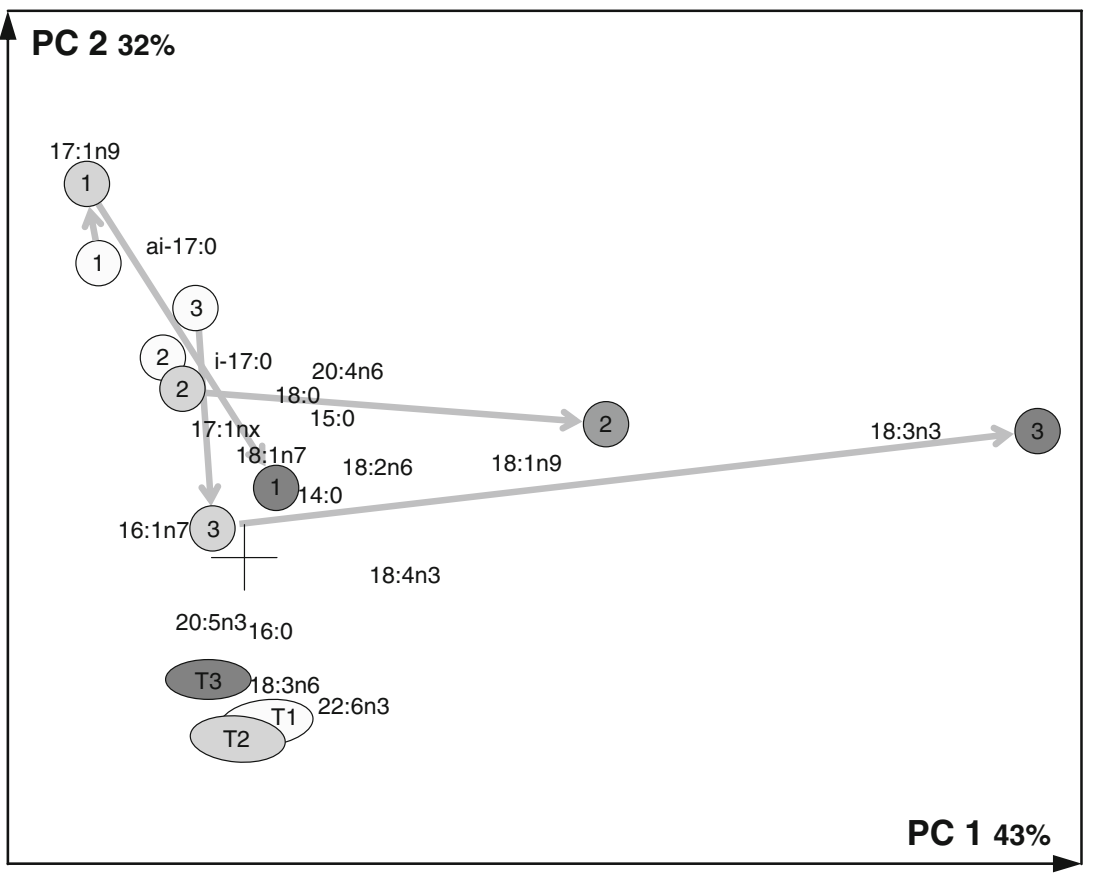

Fig. 2 Principal component $(P C)$ analysis plot. For Pavlova lutheri, all replicates from the three bags from the first sampling are located within the oval marked T1, all replicates from the three bags from the second sampling are located within the oval marked T2, and replicates from the three bags from the third sampling are located within the oval marked T3. For Chaetoceros muelleri the replicates from each bag at each sampling are located within the circles marked with 1, 2 and 3 for each of the bags. The circles with lightest shading are from the first sampling, circles from the second sampling are darker and those from the third sampling have the darkest shading. The position of the fatty acids in the plot indicates their importance for the spread of the samples: the closer the samples are located to a fatty acid the more they contain of this fatty acid relative to the other samples. The percentage of the total variation among the samples which is described by the two PCs is shown
Fig. 3 Principal component $(P C)$ analysis plot of the Pavlova lutheri samples. The replicates from each bag at each sampling are located in and around the circles marked with 1, 2 and 3 for each of the bags. The circles with lightest shading are from the first sampling, circles from the second sampling are darker and those from the third sampling have the darkest shading. The position of the fatty acids in the plot indicates their importance for the spread of the samples: the closer the samples are located to a fatty acid the more they contain of this fatty acid relative to the other samples. The percentage of the total variation among the samples which is described by the two PCs is shown

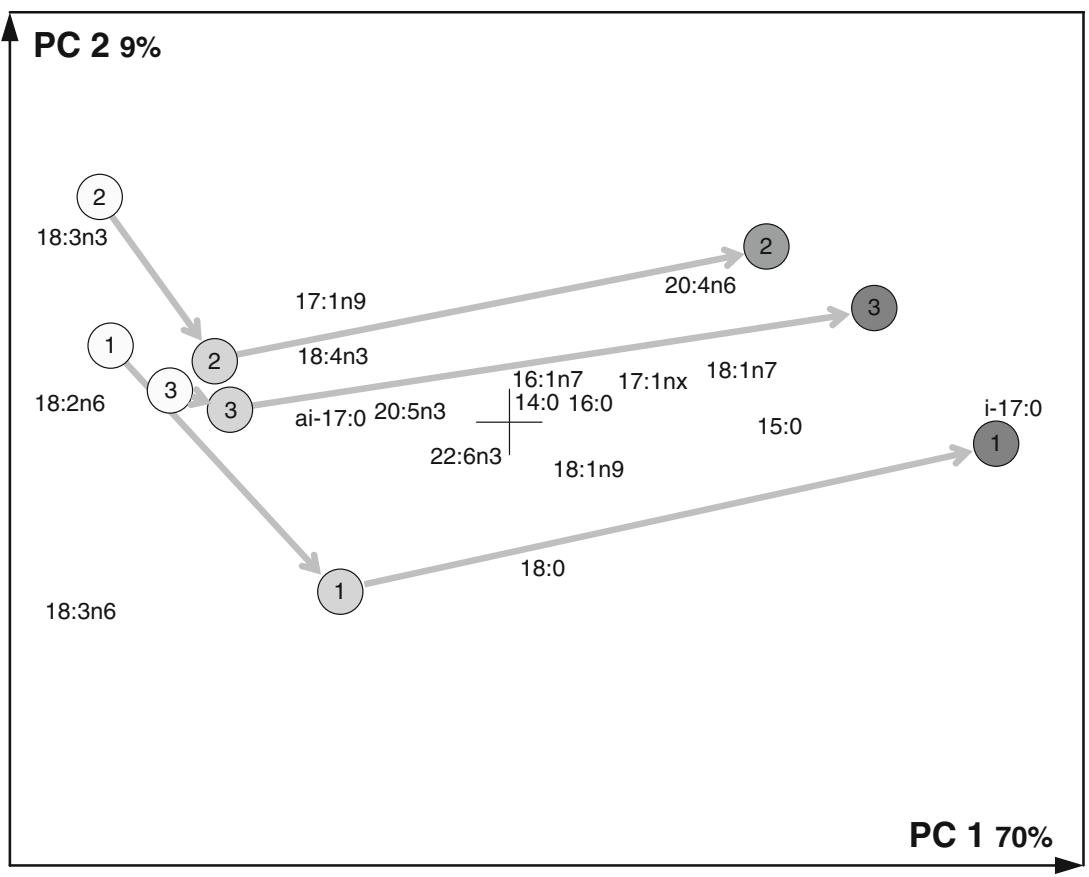




\section{Discussion}

The total fatty acid content (pg cell ${ }^{-1}$ ) increased significantly $(p<0.05)$ in all of the P. lutheri and C. muelleri bags over time. In the $P$. lutheri bags the total FA content was almost twice as high as Jacobsen et al. (2010) reported from the similar system with wider bags. Although the total FA content increased in the $C$. muelleri bags during the experiment, it was lower than contents reported by Jacobsen et al. (2010) with wider bags, but higher than Pernet et al. (2003) reported from $170 \mathrm{~L}$ semi-continuous cultures $(D=50 \mathrm{~cm})$.

An increase of the content of the essential PUFAs $\left(\mathrm{pg} \mathrm{cell}{ }^{-1}\right.$ ) from start to the end of the experiment was also observed. The content of the essential PUFAs was nearly doubled in the all of the bags. n-6 DPA (22:5n-6), which was almost absent in the present cultures, was found in both $P$. lutheri and $C$. muelleri when grown in wider bags under light limitation (Jacobsen et al. 2010).

When comparing this growth system constituting of narrow bags $(250-\mathrm{L}, D=25 \mathrm{~cm})$ with the similar system with wider bags (500-L, $D=50 \mathrm{~cm}$, Jacobsen et al. 2010), $P$. lutheri contained more of the essential PUFAs in the narrow bags, while $C$. muelleri contained more in the wider bags. In the narrow $P$. lutheri bags (this experiment) the content of EPA and DHA were almost twice as high as in the wider bags (Jacobsen et al. 2010). The content of EPA and n-6 DPA in C. muelleri were higher in the wider bags, almost equal content of ARA between narrow and wider bags, while DHA was highest in the narrow bags.

Thompson et al. (1990) investigated the influence of irradiance on the FA composition of eight species commonly used in aquaculture including $P$. lutheri and $C$. muelleri. They found that EPA and DHA increased with decreasing light intensities for C. muelleri, but decreased for $P$. lutheri. In this experiment we found that the content of the essential FAs increased in C. muelleri and P. lutheri, except for n-6 DPA. Both EPA and DHA increased in $P$. lutheri when light availability was increased compared with wider bags (Jacobsen et al. 2010). The content of ARA and EPA in C. muelleri was, respectively, equal to or higher in the wider bags with light limitation (Jacobsen et al. 2010).

The proportions (\% of total FA) of SFA, MUFA and PUFA in this experiment were similar to those found in the wider bags (Jacobsen et al. 2010). An increase of SFAs and MUFAs were observed in the P. lutheri bags, while SFAs and PUFAs increased in the $C$. muelleri bags.

Relatively high proportions of 14:0, 16:0,16:1n7 in addition to n-6 PUFAs such as $18: 2 \mathrm{n} 6,18: 3 \mathrm{n} 6$ and ARA were recorded in the $C$. muelleri bags, typical for diatoms in general (Volkman et al. 1989). The n-6 PUFAs such as ARA and n-6 DPA are considered as important FAs for scallop larvae and may have an impact on the rearing success (Parrish et al. 1998, Milke et al. 2004, 2006, 2008).
Milke et al. (2008) showed that n-6 DPA was particularly important in early life stages of Placopecten magellanicus. Our results showed that the content of ARA was stable or increasing in all of the species and bags over time. The FA n-6 DPA was not detected in any of the species in the narrow bags, which received more light than the wider bags (see also further below in discussion), but were present in a similar experiment with wider bags and probable light limitation (Jacobsen et al. 2010). This might indicate that light limitation increase content of this FA, as shown by e.g. Cheng-Wu et al. (2002).

The PC analysis detected variation between the bags and species over time (Fig. 2). PC1 represented $43 \%$ of the total variation between the samples. The second largest variation, $32 \%$, occurred along $\mathrm{PC} 2$, and is independent of the variation along PC1. The variation between bags over time was larger for $C$. muelleri than for P. lutheri. This was the opposite of what was found in the wider bags (Jacobsen et al. 2010). Different FAs contributed to the variation observed between the C. muelleri bags in this experiment. In the beginning of the experiment the content of $17: 1 \mathrm{n} 9$, ai-17:0 and $16: 1 \mathrm{n} 7$ was high, while the content of $18: 2 \mathrm{n} 6,18: 1 \mathrm{n} 9,18: 4 \mathrm{n} 3$ and $18: 3 \mathrm{n} 3$ increased towards the end of the experiment.

In this experiment temperature, culture media and $\mathrm{pH}$ were kept stable and were not limiting. The light conditions were, however, improved by reducing the bag diameter to $25 \mathrm{~cm}$, compared with the traditional set up with wider bags (Jacobsen et al. 2010). The surface area to volume relationship for light penetration was improved. With the assumptions that photosynthetic active light penetrate $3 \mathrm{~cm}$ into the culture (Richmond 2004) and the height and diameter are 240 and $25 \mathrm{~cm}$, respectively, the light limited internal zone of the bags was $76 \%$ of the total area of the bags. With the same assumption the light limited internal zone of the wider bags $(D=50 \mathrm{~cm}$; Jacobsen et al. 2010) was $88 \%$ of the total area. By reducing the diameter of the bags from $50 \%$ to $25 \mathrm{~cm}$ the culture received $12 \%$ more light compared with the wider bags. This increased light availability resulted in increased cell density and FA content. The cell density was almost tripled when compared with the wider bags (Jacobsen et al. 2010).

In conclusion, the results from this experiment indicate that flagellates such as $P$. lutheri perform better in narrow bags with improved light conditions, while diatoms like $C$. muelleri perform better in wider bags under light limitation. In the P. lutheri bags the cell numbers increased and the content of the essential FAs increased as EPA and DHA were doubled. In C. muelleri cell numbers also increased and the content of DHA increased, but not as much as in wider bags (Jacobsen et al. 2010).

The results indicate that bivalve hatcheries should consider to grow different species in different bag sizes and light conditions depending on light preferences. A 
production design with a mixture of both narrow and wide bags would be optimal in respect to essential FA production when both diatoms and flagellates are present.

Acknowledgements We would like to thank the staff at Scalpro AS hatchery and Charlotte Grannefors-Kraft for assistance during the experiment. This work was funded by Scalpro AS and the Research Council of Norway (project no.180001/S40).

Open Access This article is distributed under the terms of the Creative Commons Attribution Noncommercial License which permits any noncommercial use, distribution, and reproduction in any medium, provided the original author(s) and source are credited.

\section{References}

Acién Fernández FG, García Camacho F, Sánchez Perez JA, Fernández Sevilla JM, Molina Grima E (1998) Modelling of biomass productivity in tubular photobioreactors for microalgal cultures: effects of dilution rate, tube diameter and solar irradiance. Biotechnol Bioeng 58:605-616

Acién Fernández FG, Sánchez Perez JA, Fernández Sevilla JM, García Camacho F, Molina Grima E (2000) Modeling of Eicosapentaenoic acid (EPA) production from Phaeodactylum tricornutum cultures in tubular photobioreactors. Effects of dilution rate, tube diameter, and solar irradiance. Biotechnol Bioeng 68:173-183

Acién Fernández FG, Hall DO, Cañizares Guerrero E, Krishna Rao K, Molina Grima E (2003) Outdoor production of Phaeodactylum tricornutum biomass in a helical reactor. J Biotechnol 103:137-152

Andersen P, Throndsen J (2003) Estimating cell numbers. In: Gm H, Anderson DM, Cembella AD (eds) Manual on harmful marine microalgae. UNESCO, Paris, pp 99-129

Ben-Amotz A, Tornabene TG, Thomas WH (1985) Chemical profiles of selected species of microalgae with emphasis on lipids. J Phycol 21:72-81

Briassoulis D, Panagakis P, Chionidis M, Tzenos D, Lalos A, Tsinos C, Berberidis K, Jacobsen A (2010) An experimental helicaltubular photobioreactor for continuous production Nannochloropsis sp. Bioresour Technol 101:6768-6777

Brown MR, Dunstan GA, Jeffrey SW, Volkman JK, Barrett SM, LeRoi JM (1993) The influence of irradiance on the biochemical composition of the prymnesiophyte Isochrysis sp. (clone T-iso). J Phycol 29:601-612

Brown MR, Jeffery SW, Volkman JK, Dunstan GA (1997) Nutritional properties of microalgae for mariculture. Aquaculture 155:315-331

Cheng-Wu Z, Cohen Z, Khozin-Goldberg I, Richmond A (2002) Characterization of growth and arachidonic acid production of Parietochloris incisa comb. nov (Trebouxiophyceae, Chlorophyta). J Appl Phycol 14:453-460

Dhert P, Sorgeloos P (1994) Live feeds in aquaculture. In: Proceedings of Aquatech'94, Colombo, Sri Lanka, 29-31 August

Dunstan GA, Volkman JK, Barrett SM, Garland CD (1993) Changes in the lipid composition and maximisation of the polyunsaturated fatty acid content of three microalgae grown in mass culture. $J$ Appl Phycol 5:71-83

Emdadi D, Berland B (1989) Variation in lipid class compositionduring batch growth of Nannochloropsis salina and Pavlova lutheri. Mar Chem 26:215-225

Guckert JB, Cooksey KE (1990) Triglyceride accumulation and fatty acid profile changes in Chlorella (Chlorophyta) during high $\mathrm{pH}-$ induced cell cycle inhibition. J Phycol 26:72-79

Hodgson PA, Henderson RJ, Sargent JR, Leftley JW (1991) Patterns of variation in the lipid class and fatty acid composition of
Nannochloropsis oculata (Eustigmatophyceae) during batch culture I. The growth cycle. J Appl Phycol 3:169-181

$\mathrm{Hu}$ Q, Richmond A (1996) Productivity and photosynthetic efficiency of Spirulina platensis as affected by light intensity, algal density and rate of mixing in a flat plate photobioreactor. J Appl Phycol 8:139-145

Jacobsen A, Grahl-Nielsen O, Magnesen T (2010) Does a large-scale continuous algal production system provide a stable supply of fatty acids to bivalve hatcheries. J Appl Phycol. doi:10.1007/ s10811-010-9518-6

James CM, Al-Hinty S, Salman AE (1989) Growth and $\omega 3$ fatty acid and amino acid composition of microalage under different temperature regimes. Aquaculture 77:337-357

Janssen MGJ, Tramper J, Mur LR, Wijffels RH (2003) Light regime, photosynthetic efficiency, scale up, and future prospects. Biotechnol Bioeng 81:193-210

Kvalheim OM, Karstang TV (1987) A general purpose program for multivariate data-analysis. Chemometr Intell Lab Syst 2:235-237

Laing I (1991) Cultivation of marine unicellular algae. MAFF Laboratory Leaflet Number 67. Directorate of Fisheries Research, Lowestoft, p 31

Magnesen T, Bergh Ø, Christophersen G (2006) Yields of great scallop, Pecten maximus, larvae in a commercial flow-through rearing system in Norway. Aquacult Int 14:377-394

Meier S, Mjøs SA, Joensen H, Grahl-Nielsen O (2006) Validation of a one-step extraction/ methylation method for determination of fatty acids and cholesterol in marine tissues. J Chromatog A 1104:291-298

Milke LM, Bricelj VM, Parrish CC (2004) Growth of postlarval sea scallops, Placopecten magellanicus, on microalgal diets, with emphasis on the nutritional role of lipids and fatty acids. Aquaculture 234:293-317

Milke LM, Bricelj VM, Parrish CC (2006) Comparison of early life history stages of the bay scallop, Argopecten irradians: effects of microalgal diets on growth and biochemical composition. Aquaculture 260:272-289

Milke LM, Bricelj VM, Parrish CC (2008) Biochemical characterization and nutritional value of three Pavlova spp. in unialgal and mixed diets with Chaetoceros muelleri for postlarval sea scallops, Placopecten magellanicus. Aquaculture 276:130-142

Parrish CC, Wells JS, Yang Z, Dabinett P (1998) Growth and lipid composition of scallop juveniles, Placopecten magellanicus, fed the flagellate Isochrysis galbana with varying lipid composition and the diatom Chaetoceros muelleri. Mar Biol 133:461-470

Pernet F, Tremblay R, Demers E, Roussy M (2003) Variation of lipid class and fatty acid composition of Chaetoceros muelleri and Isochrysis sp. grown in a semicontinuous system. Aquaculture 221:393-406

Richmond A (2004) Handbook on microalgal culture: biotechnology and applied phycology. Iowa State Press/Blackwell, Iowa

Thompson PA, Harrison PJ, Whyte JNC (1990) Influence of irradiance on the fatty acid composition of phytoplankton. J Phycol 26:278-288

Thompson PA, Guo M-X, Harrison PJ (1992) Effects of variation in temperature. I. On the biochemical composition of eight species of marine phytoplankton. J Phycol 28:481-488

Volkman JK, Jeffrey SW, Nichols PD, Rogers GI, Garland CD (1989) Fatty acid and lipid composition of 10 species of microalgae used in mariculture. J Exp Mar Biol Ecol 128:219-240

Zhu CJ, Lee YK, Chao TM (1997) Effects of temperature and growth phase on lipid and biochemical composition of Isochrysis galbana TK1. J Appl Phycol 9:451-457

Zou N, Zhang C, Cohen Z, Richmond A (2000) Production of cell mass and eicosapentaenoic acid (EPA) in ultrahigh cell density cultures of Nannochloropsis sp. (Eustigmatophyceae). Eur J Phycol 35:127-133 